\title{
Non-controlled Fault Current Limiter to Improve Fault Ride through Capability of DFIG-Based Wind Turbine
}

\author{
Seyed Behzad Nderi ${ }^{1}$, Michael Negnevistky ${ }^{1}$, Amin Jalilian ${ }^{2}$, Mehrdad Tarafdar Hagh $^{3}$ \\ ${ }^{1}$ School of Engineering and ICT, University of Tasmania, Hobart, TAS, 7001, Australia \\ ${ }^{2}$ Young Researchers and Elite Club, Kermanshah Branch, Islamic Azad University, Kermanshah, Iran \\ ${ }^{3}$ Faculty of Electrical and Computer Engineering, University of Tabriz, Tabriz 51666-15813, Iran \\ E-mail addresse: Seyedbehzad.Naderi@utas.edu.au (S. B. Naderi)
}

\begin{abstract}
In this paper, a non-controlled fault current limiter (FCL) is proposed to improve fault ride through capability of doubly fed induction generator (DFIG)-based wind turbine. Cooperative operation of chopper circuit and the non-controlled FCL, which is located in rotor side of the DFIG, is studied. It is demonstrated that locating the proposed topology in the rotor side is effective from leakage coefficient point of view in limiting transient over currents rather than stator side. Furthermore, it is shown that, by obtaining optimum non-superconducting reactor value, rate of fault current change is limited to lower than maximum rate of current change in semiconductor switches of the DFIG's converters during fault. Design methodology of non-superconducting reactor value is investigated. Operation of the non-controlled FCL in the rotor side is compared to crowbar protection scheme and results will be discussed. PSCAD/EMTDC software is employed to simulate the proposed scheme and prove its effectiveness.
\end{abstract}

Index Terms - doubly fed induction generator; fault ride through; leakage coefficient; non-controlled fault current limiter; non-superconducting reactor.

\section{INTRODUCTION}

Nowadays, due to many salient features of doubly fed induction generator (DFIG)-based wind turbine, they are mainly employed as wind energy conversation systems (WECSs) for above applications $1 \mathrm{MW}$ [1]. By increasing the penetration level of the DFIG-based wind turbine in the power system and also considering "E.ON" grid code, the strict one, the wind turbines have to keep connected for $150 \mathrm{~ms}$ during zero voltage condition [2]. Consequently, the grid operators force the wind turbines to stay connected with the utility during fault conditions. This operational behavior is known as fault ride-through (FRT) capability [3]. The DFIG employs partially scale back-to-back voltage-source converters (VSCs), rotor side converter (RSC) and grid side converter (GSC), with limited over-current withstand capability in semiconductor switches utilized in the converters [4]. Whenever a short circuit fault occurs in the grid, high transient over-currents are injected from the rotor and pass through the RSC. These over-currents may exceed maximum permissible fault current of semiconductor devices. So, this situation can either trip out the DFIG or damage its power electronic components during fault condition. Therefore, DFIG cannot continuously operate during the fault without any protection measures [5]. Meanwhile, the DFIG is very sensitive to asymmetrical grid faults, which causes highest transient over currents [6].

Up to now, many different methods have been investigated to enhance the FRT capability of the DFIG-based wind turbine. These schemes can be divide into two categories. The first one is advanced control methods, which are employed to improve the operational behavior of the back to back converters during the fault and inject reactive power to improve the voltage stability in the terminal of the DFIG [7, 8]. During zero voltage sag, these methods are not so suitable and also their complexity make them hard to be implemented by industry.

The second method is to add new structure in the configuration of the DFIG. Dynamic voltage restores (DVRs), static synchronous compensator (STATCOM), unified power quality controller (UPQC), and static VAR compensator (SVC) are applied to compensate voltage sag in the grid side of the DFIG [9-12]. The mentioned structures use many numbers of the self-turn off switches and need more measurements. Fault current limiters (FCLs), and series dynamic breaking resister (SDBR) are effective to limit the fault current level both in the stator and the rotor side [13-16]. However, both the FCLs and the SDBRs require some measurements and also in the SDBRs, they need continuous controlled switching during the normal operation. Furthermore, some structures of the FCLs utilize inductive type of superconductor, which increases initial and maintenance costs of the FCLs. The most general method is crowbar protection, which de-energizes the rotor and bypasses the RSC during the fault [17]. The crowbar changes the DFIG to squirrel cage induction generator, which does not comply the grid code requirements $[2,17]$.

This paper introduces a non-controlled FCL to enhance the FRT capability of the DFIG-based wind turbine during symmetrical and asymmetrical grid faults. The non-controlled FCL has low cost and does not require any measurement to control the fault current. The proposed structure is located in series with the rotor of the DFIG. It is proved that, from leakage coefficient point of view, locating the non-controlled FCL in the rotor side can be so effective in limiting transient 
over currents in the converters rather than the stator side. The value of leakage coefficient is computed for location of the non-controlled FCL both in the rotor side and the stator side. By operation of the non-controlled FCL and calculating the optimum value of the non-superconducting reactor of the proposed method, high raising rate of the fault current could be reduced to lower than $d i_{\max } / d t$ of the semiconductor switches of the RSC. Furthermore, the operation of the proposed scheme is compared to the most common FRT method, the crowbar protection. The results show that the noncontrolled FCL has effective operation in comparison with the crowbar protection. The configuration of the non-controlled FCL is simple and can be easily utilized by the industry. The simulation is done by PSCAD/EMTDC software for all grid faults, which proves the effectiveness of the proposed FRT scheme.

\section{The Proposed Non-CONTROLled FAult CurRent LIMITER TO IMPROVE FRT CAPABILITY OF THE DFIG}

The configuration of the DFIG-based wind turbine equipped with the non-controlled FCL in the rotor side is shown in Fig. 1. The non-controlled FCL structure includes a three single phase isolated transformer, a three phase rectifier diode bridge and a non-superconducting reactor. During the normal operation of the DFIG-based wind turbine, the nonsuperconducting reactor is charged to the peak of rotor line current and its inherent resistance causes small voltage drop, which depends on the peak of line current of the rotor. However, instead of using non-superconducting reactor, the superconducting one can be employed. But, both the initial and maintenance cost increase. Furthermore, it is required to allocate large volume of cooling system for the superconductor, which increases space of the FCL installation [18].

When a fault happens, including symmetrical or asymmetrical, the fault current tends to increase, suddenly, which may damage the semiconductor switches of the RSC. By employing the non-controlled FCL, the rate of current change is suppressed to a desired value, which should be lower than $d i_{\max } / d t$ of the semiconductor switches. The calculation of non-superconducting reactor is mentioned in the section III. Also, during the fault, due to voltage sag in the terminal of the stator, the DFIG is not able to deliver active power to the grid. So, DC link voltage increases. The DC chopper circuit operates to discharge DC link capacitor and keep its voltage in a desired value.

III. Calculation Procedure of the NonSUPERCONDUCTING REACTOR IN THE PROPOSED METHOD CONSIDERING THE PARK MODEL OF THE DFIG

Considering the Park model of the DFIG [19], the rotor and stator voltages, $\vec{u}_{r}, \vec{u}_{s}$, and fluxes, $\vec{\psi}_{r}, \vec{\psi}_{s}$, are expressed as follows:

$$
\begin{aligned}
& \vec{u}_{s}=R_{s} \vec{i}_{s}+\frac{d \vec{\psi}_{s}}{d t} \\
& \vec{u}_{r}=R_{r} \vec{i}_{r}+\frac{d \vec{\psi}_{r}}{d t} \\
& \vec{\psi}_{s}=L_{s} \vec{i}_{s}+L_{m} \vec{i}_{r} \\
& \vec{\psi}_{r}=L_{m} \vec{i}_{s}+L_{r} \vec{i}_{r}
\end{aligned}
$$

$R$ and $L$ denote resistance and inductance, respectively. Subscripts of $m, s$, and $r$ represent mutual, stator, and rotor parameters, respectively. To calculate $\psi_{r}$ in terms of $i_{r}$ and $\psi_{s},(3)$ and (4) are used. As a result:

$$
\vec{\psi}_{r}=\frac{L_{m} \vec{\psi}_{s}}{L_{s}}+\sigma L_{r} \vec{i}_{r}
$$

where $\sigma$ is the leakage coefficient, which is equal to $1-L_{m}^{2} / L_{s} L_{r}$. Considering (2) and (5), it is concluded that:

$$
\vec{u}_{r}=\frac{L_{m}}{L_{s}} \frac{d \vec{\psi}_{s}}{d t}+\left(R_{r}+\sigma L_{r} \frac{d}{d t}\right) \vec{i}_{r}
$$

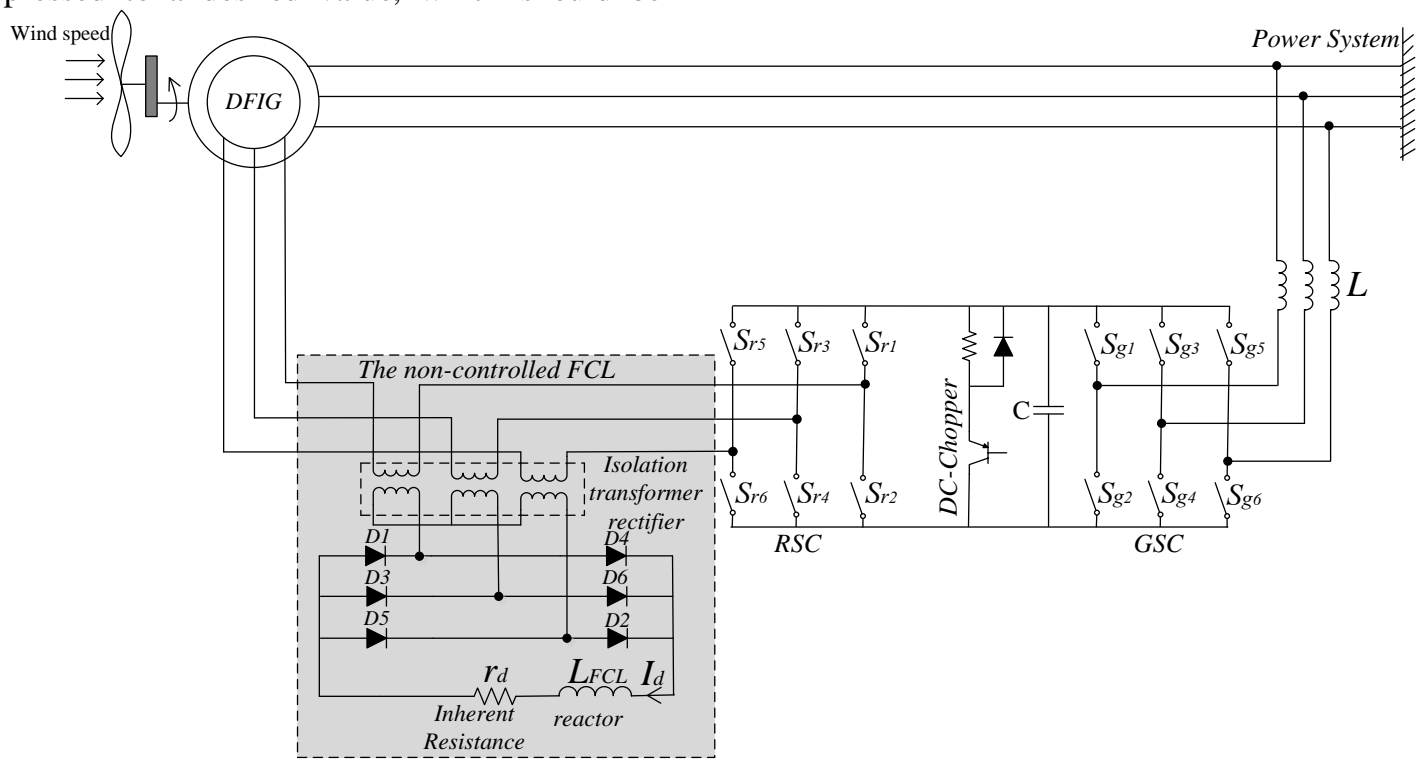

Figure 1. The proposed configuration of the non-controlled fault current limiter located in the rotor side of the DFIG 
By operation of the proposed non-controlled FCL in the rotor side during the fault, the non-superconducting reactor $\left(L_{F C L}\right)$ enters to the rotor side current pass because of sudden increasing the rotor side current. In this situation, $L_{r}$ is changed to $L_{r}+a^{2} L_{F C L}$, where $a$ is the isolation transformer ratio. So, by using (3) and (4), the value of leakage coefficient is expressed as follows:

$$
\sigma_{\text {rotor side } F C L}=1-\frac{L_{m}^{2}-a^{2} L_{F C L} L_{S}}{L_{s} L_{r}}
$$

It is clear that inserting $L_{F C L}$ increases $\sigma_{\text {rotor side } F C L}$. Therefore, the transient over currents in the rotor side can be suppressed, effectively. The worse condition for the DFIG is during phase to phase fault as the asymmetrical grid fault [6]. In this condition, the first term of (6), the back EMF, has maximum value, which causes severe rotor transient current. The maximum value of back EMF can be expressed as follows [13]:

$$
\left|V_{E M F, M A X}\right| \approx 2.4 \frac{L_{m}}{L_{s}} V_{S}
$$

that $V_{s}$ is the maximum value of the stator or terminal voltage of the DFIG. To calculate the optimum value of $L_{F C L}$ regarding the semiconductor switch specifications, the worse condition is considered. At the first moment of the fault, because the charging process of $L_{F C L}$ begins, the initial rate of current change will have the maximum value. Therefore, if the maximum value of the rotor current during the normal operation of the DFIG is shown by $i_{r, \max }$, considering (6) and (7), (9) can be written as follows:

$$
\left\{\begin{array}{c}
\sigma_{M I N, \text { rotor side } F C L}=\frac{\left|\vec{u}_{r, \text { max }}\right|+2.4 \frac{L_{m}}{L_{S}} V_{S}+R_{r}\left|\vec{i}_{r, \max }\right|}{L_{r}\left|\frac{d}{d t} i_{\text {max }}\right|} \\
L_{F C L}>\frac{L_{S} L_{r}\left(\sigma_{M I N, \text { rotor side } F C L}-1\right)+L_{m}^{2}}{a^{2} L_{S}}
\end{array}\right.
$$

With regard to (9), it is obvious that $\sigma_{M I N \text {,rotor side FCL }}$ depends on the maximum voltage generated by the rotor, the voltage level of the stator, and the maximum value of the rotor current during the normal operation. As a result, considering these parameters, the minimum value of $L_{F C L}$ can be computed to achieve desired rate of fault current change during the worse condition.

As mentioned above, the location of the non-controlled FCL is important from the leakage coefficient point of view. In fact, for especial value of $L_{F C L}$, the impact of the proposed method on limiting the transient over current in the RSC can be changed. If the proposed FCL is located in the stator side of the DFIG, $L_{s}$ increases to $L_{s}+a^{2} L_{F C L}$ after operation of the proposed scheme. With regard to (3) and (4), the leakage coefficient can be calculated as follows:

$$
\sigma_{\text {stator side } F C L}=1-\frac{L_{m}^{2}}{\left(L_{S}+a^{2} L_{F C L}\right) L_{r}}
$$

Considering (7) and (10) and comparing $\sigma_{\text {rotor side } F C L}$ and $\sigma_{\text {stator side } F C L}$ reveals that increasing $L_{F C L}$ has more effect on increasing the value of $\sigma_{\text {rotor side FCL. }}$. So, in the DFIG-based wind turbine, employing the non-controlled FCL in the rotor side is more effective rather than the stator side of the DFIG in restricting the transient over currents in the RSC.

\section{Simulation Results}

Fig 2 is used to simulate the operation of the DFIG based wind turbine during the power system grid faults. The DFIG is connected to the power system through three phase transformer, $0.69 / 34.5 \mathrm{kV}, \quad 60 \mathrm{~Hz}, \quad 5 M V A$, and parallel transmission lines, $30 \mathrm{~km}, 0.01+\mathrm{j} 0.1 \Omega / \mathrm{km}$. The parameters of the DFIG-based wind turbine is $0.69 \mathrm{kV}, 2 \mathrm{MVA}, 60 \mathrm{~Hz}$. Due to page limitation, detailed parameters and control block diagrams of both the RSC and the GSC have not been mentioned here. For more details, [20] is referred. In the proposed non-controlled FCL, value of $L_{F C L}$ is $0.2 \mathrm{H}$, which effectively limits the rate of transient over currents in the RSC. Voltage drop on diodes of the three phase diode bridge rectifier is $3 V$. Parameters of the isolation transformer are $a=$ 1, 0.2p.u., $1 M V A$.

Two case studies are considered in the simulation section. In both case studies, the operation of the non-controlled FCL is compared to the crowbar protection as most common FRT capability improvement in the DFIG-based wind turbine. The fault happens at $t=3 \mathrm{~s}$, and continues for $150 \mathrm{~ms}$. Wind speed is $14 \mathrm{~m} / \mathrm{s}$ and the DFIG mode of operation is in supersynchronous speed. Meanwhile, the DC chopper operates when the DC link voltage reaches to threshold value of 1.1p.u. To consider the worse condition, the fault location is at the beginning of the transmission lines at point $\mathrm{F}$ in Fig. 2.

\section{A. Case Study I: Symmetrical Grid Fault: Three Phase Fault}

Fig. 3 and 4 show the operation of DFIG-based wind turbine with the crowbar protection and the proposed noncontrolled FCL in the rotor side, respectively. Because of page limitation, only key variables are presented.

As it is obvious from Fig. 3(a), the three phase fault happens in the terminal of the DFIG, and the stator voltage is zero in all three phases, approximately. Considering the stator currents, Fig. 3(b) and Fig. 4(b), it is clear that employing the proposed method limits the stator current up to 1.5p.u. during the fault. But, by the crowbar protection, the stator current increases up to 2.5p.u. The rotor transient over currents are shown in Fig. 3(c) and 4(c). The results represent that the noncontrolled FCL located in the rotor side is effective compared to the crowbar protection. The proposed scheme restricts the transient over currents of the rotor to almost $2 p . u$. Fig. 3(d) and 4(d) present the DC link voltage. Due to the DC chopper operation, the DC link voltage is kept constant in 1.1p.u. The rotor speed is illustrated in Fig. 3(e) and Fig 4(e). Considering Fig. 3(f) and 4(f), by using the proposed scheme, first peak of the electrical torque is smoothed compared to the crowbar

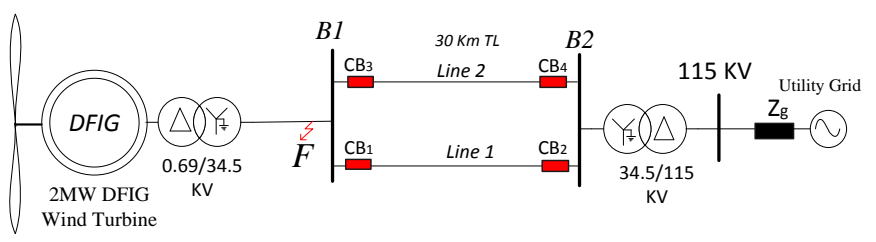

Figure 2. The simulated power system 


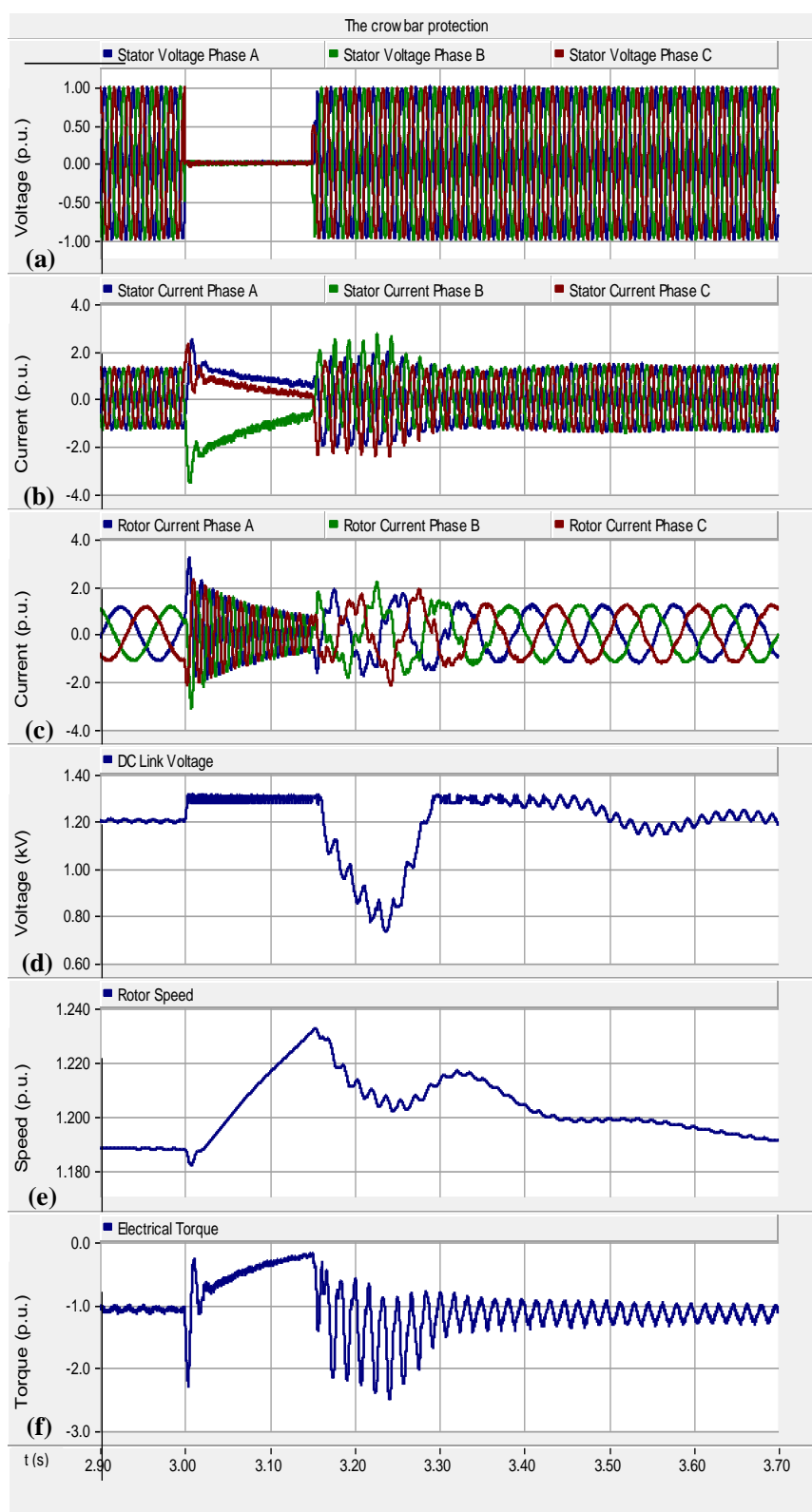

Figure 3. The crowbar protection, (a) stator voltage, (b) stator current, (c) rotor current, (d) DC link voltage, (e) rotor speed, (f) electrical torque

protection. As a result, lifetime of mechanical parts of the DFIG-can be improved. Finally, the non-superconducting reactor current of the proposed FCL is shown in Fig. 4(a). After fault occurring, the raising slope of the rotor current is effectively decreased. After fault removal, the reactor is discharged by its inherent resistance and voltage drops on the three phase diode bridge rectifier. Therefore, the noncontrolled FCL will be ready to any possible fault in the power system.

\section{B. Case Study II: Asymmetrical Grid Fault: Phase to Phase Fault}

As mentioned, the DFIG is very sensitive to the asymmetrical grid faults. In this section, the phase to phase fault, phase A and B to ground, is considered to evaluate and compare the operation of non-controlled FCL. In Fig. 5, the

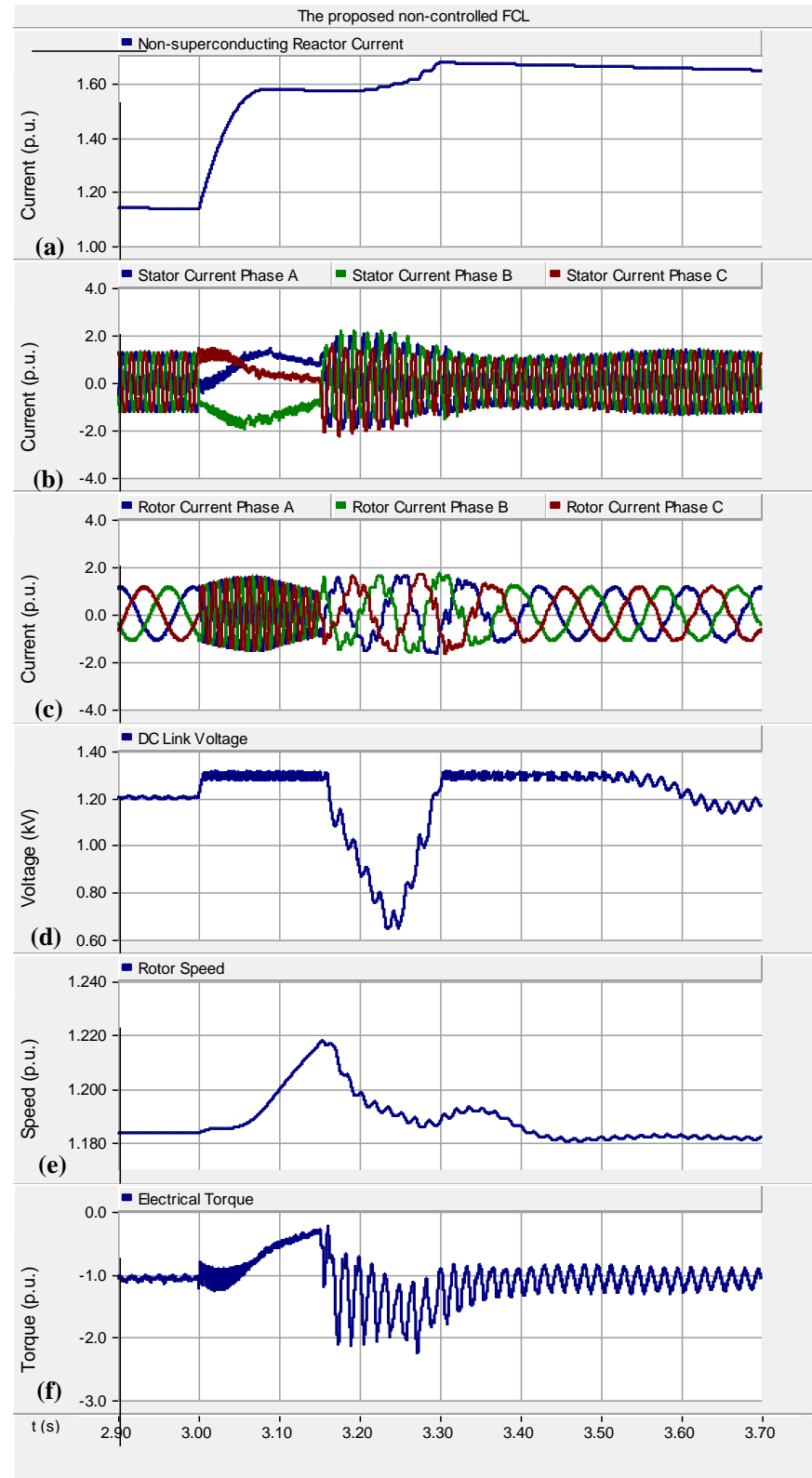

Figure 4. The proposed scheme, (a) non-superconductng reactor current, (b) stator current, (c) rotor current, (d) DC link voltage, (e) rotor speed, (f) electrical torque

stator and the rotor currents are represented as key parameters with the crowbar protection. As it is clear, the stator currents have large oscillations during the fault (Fig. 5(a)). The current level increases up to $4 p . u$. The same condition happens in the rotor currents (Fig. 5(b)). By employing the proposed noncontrolled FCL, both the stator (Fig. 6(a)) and the rotor currents (Fig. 6(b)) are mitigated to $2 p . u$. To sum up, locating the proposed FCL in the rotor side is effective solution from both current limiting and cost point of view.

\section{CONCLUSION}

In this paper, the non-controlled fault current limiter has been proposed to improve the fault ride through capability of the DFIG-based wind turbine. It was shown that locating the non-controlled FCL in the rotor side is effective to restrict the rotor transient over currents from the leakage coefficient point 


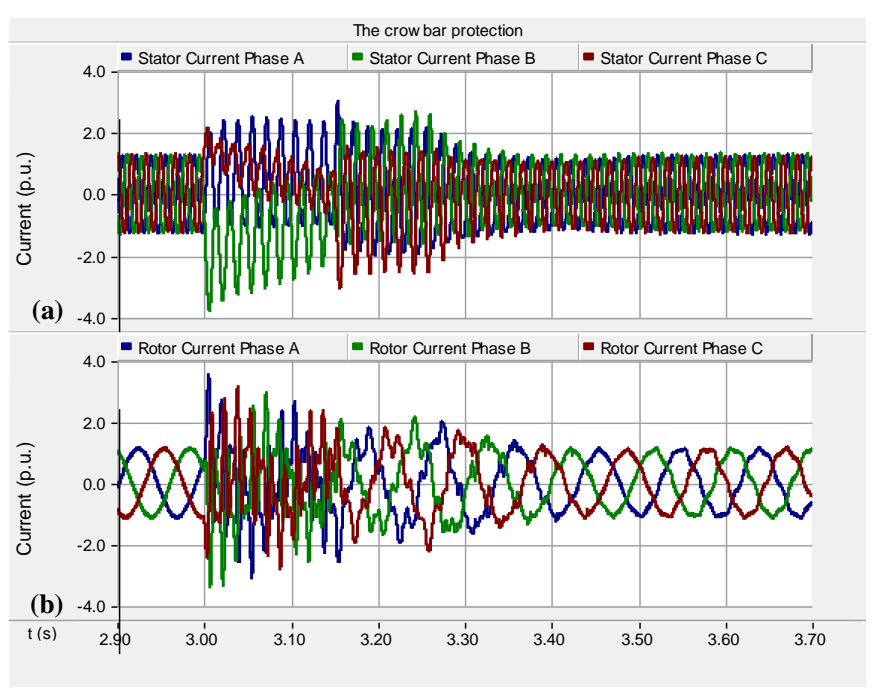

Figure 5. The crowbar protection, (a) stator current, (b) rotor current

of view rather than the stator side. Operation of the proposed scheme was compared to the crowbar protection. Two case studies have been investigated, three phase fault and phase to phase fault. Meanwhile, calculation procedure of the optimum value of the non-superconducting reactor has been done. By optimum value of the reactor, it is guarantee that the rate of fault current change is lower than $d i_{\max } / d t$ of the semiconductor switches of the rotor side converter. The proposed scheme does not require any measurement to limit the rotor fault current during the fault. Its configuration is simple and can be easily utilized by the industry. PSCAD/EMTDC software has been employed to evaluate the operation of the non-controlled FCL during all fault scenarios, including symmetrical and asymmetrical grid faults.

\section{REFERENCES}

[1] S. Jing, T. Yuejin, X. Yajun, R. Li, and L. Jingdong, "SMES Based Excitation System for Doubly-Fed Induction Generator in Wind Power Application," Applied Superconductivity, IEEE Transactions on, vol. 21, pp. 1105-1108, 2011.

[2] E. Netz, "Grid code; high and extra high voltage," E-One Netz GmbH, Bayreuth, vol. 4, 2006.

[3] M. E. Elshiekh, D. A. Mansour, and A. M. Azmy, "Improving Fault Ride-Through Capability of DFIG-Based Wind Turbine Using Superconducting Fault Current Limiter," Applied Superconductivity, IEEE Transactions on, vol. 23, pp. 5601204-5601204, 2013.

[4] A. Jalilian, M. T. Hagh, M. Abapour, and K. M. Muttaqi, "DC-link fault current limiter-based fault ride-through scheme for inverter-based distributed generation," Renewable Power Generation, IET, vol. 9, pp. 690-699, 2015.

[5] J. Lopez, E. Gubia, P. Sanchis, X. Roboam, and L. Marroyo, "Wind Turbines Based on Doubly Fed Induction Generator Under Asymmetrical Voltage Dips," Energy Conversion, IEEE Transactions on, vol. 23, pp. 321-330, 2008.

[6] G. Hua, L. Cong, and Y. Geng, "LVRT Capability of DFIG-Based WECS Under Asymmetrical Grid Fault Condition," Industrial Electronics, IEEE Transactions on, vol. 60, pp. 2495-2509, 2013.

[7] H. Fathabadi, "Control of a DFIG-based wind energy conversion system operating under harmonically distorted unbalanced grid voltage along with nonsinusoidal rotor injection conditions," Energy Conversion and Management, vol. 84, pp. 60-72, 8// 2014.

[8] X. Dongliang, X. Zhao, Y. Lihui, J. Ostergaard, X. Yusheng, and W. Kit Po, "A Comprehensive LVRT Control Strategy for DFIG Wind Turbines With Enhanced Reactive Power Support," Power Systems, IEEE Transactions on, vol. 28, pp. 3302-3310, 2013.

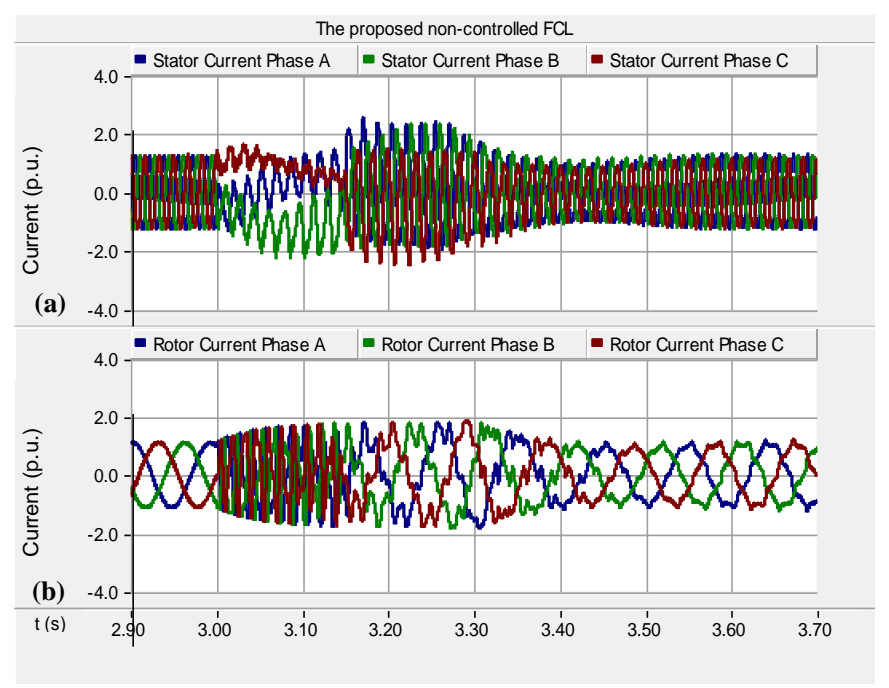

Figure 6. The proposed scheme, (a) stator current, (b) rotor current

[9] S. Alaraifi, A. Moawwad, M. S. El Moursi, and V. Khadkikar, "Voltage Booster Schemes for Fault Ride-Through Enhancement of Variable Speed Wind Turbines," Sustainable Energy, IEEE Transactions on, vol. 4, pp. 1071-1081, 2013.

[10] A. F. Abdou, A. Abu-Siada, and H. R. Pota, "Application of STATCOM to improve the LVRT of DFIG during RSC fire-through fault," in Universities Power Engineering Conference (AUPEC), 2012 22nd Australasian, 2012, pp. 1-6.

[11] M. A. Saleh, M. N. Eskander, S. Amer, and M. N. F. Nashed, "Enhancing the LVRT capability of grid connected wind energy conversion system using Unified Power Quality Controller," in Transportation Electrification Asia-Pacific (ITEC Asia-Pacific), 2014 IEEE Conference and Expo, 2014, pp. 1-5.

[12] T. Masaud and P. K. Sen, "A comparative study of the implementation of STATCOM and SVC on DFIG-based wind farm connected to a power system," in Power and Energy Society General Meeting, 2012 IEEE, 2012, pp. 1-1.

[13] G. Wenyong, X. Liye, D. Shaotao, L. Yuanhe, X. Xi, Z. Weiwei, et al., "LVRT Capability Enhancement of DFIG With Switch-Type Fault Current Limiter," Industrial Electronics, IEEE Transactions on, vol. 62, pp. 332-342, 2015.

[14] M. Mardani and S. H. Fathi, "Fault current limiting in a wind power plant equipped with a DFIG using the interface converter and an optimized located FCL," in Power Electronics, Drives Systems \& Technologies Conference (PEDSTC), 2015 6th, 2015, pp. 328-333.

[15] I. Ngamroo and T. Karaipoom, "Improving Low-Voltage Ride-Through Performance and Alleviating Power Fluctuation of DFIG Wind Turbine in DC Microgrid by Optimal SMES With Fault Current Limiting Function," Applied Superconductivity, IEEE Transactions on, vol. 24, pp. 1-5, 2014.

[16] M. A. H. Soliman, H. Soliman, and P. K. Soori, "Analysis of the dynamic behavior and LVRT capability of a DFIG using SDBR during grid disturbances," in GCC Conference and Exhibition (GCC), 2013 7th IEEE, 2013, pp. 436-439.

[17] G. Pannell, D. J. Atkinson, and B. Zahawi, "Minimum-Threshold Crowbar for a Fault-Ride-Through Grid-Code-Compliant DFIG Wind Turbine," Energy Conversion, IEEE Transactions on, vol. 25, pp. 750759,2010

[18] S. B. Naderi, M. Jafari, and M. Tarafdar Hagh, "Parallel-resonancetype fault current limiter," Industrial Electronics, IEEE Transactions on, vol. 60, pp. 2538-2546, 2013.

[19] J. Lopez, P. Sanchis, X. Roboam, and L. Marroyo, "Dynamic Behavior of the Doubly Fed Induction Generator During Three-Phase Voltage Dips," Energy Conversion, IEEE Transactions on, vol. 22, pp. 709-717, 2007.

[20] G. Abad, J. Lopez, M. Rodríguez, L. Marroyo, and G. Iwanski, Doubly fed induction machine: modeling and control for wind energy generation vol. 85: John Wiley \& Sons, 2011. 